University of Nebraska - Lincoln

DigitalCommons@University of Nebraska - Lincoln

Architectural Engineering -- Faculty Publications

Architectural Engineering and Construction,

Durham School of

3-2006

Room Acoustics in Coupled Volume Spaces

David T. Bradley

University of Nebraska - Lincoln

Lily M. Wang

University of Nebraska - Lincoln, Iwang4@unl.edu

Follow this and additional works at: https://digitalcommons.unl.edu/archengfacpub

Part of the Architectural Engineering Commons

Bradley, David T. and Wang, Lily M., "Room Acoustics in Coupled Volume Spaces" (2006). Architectural Engineering -- Faculty Publications. 12.

https://digitalcommons.unl.edu/archengfacpub/12

This Article is brought to you for free and open access by the Architectural Engineering and Construction, Durham School of at DigitalCommons@University of Nebraska - Lincoln. It has been accepted for inclusion in Architectural Engineering -- Faculty Publications by an authorized administrator of DigitalCommons@University of Nebraska Lincoln. 


\title{
Room Acoustics in Coupled Volume Spaces
}

\author{
David T. Bradley and Lily M. Wang
}

Architectural Engineering Program, University of Nebraska - Lincoln, Peter Kiewit Institute, 1110 S. 67th Street, Omaha, NE 68182-068; PH (402) 554-2074; FAX (402) 554-2080; email: dbradley3@unl.edu

\begin{abstract}
The study of sound in the built environment is finding more awareness in the $21^{\text {st }}$ century. As this awareness has increased, and as computing power has grown, the method of computer modeling for studying room acoustics in such settings as classrooms, offices, and performances spaces has taken great strides in recent years. Of particular interest has been the study of the coupled volume space due to its unique ability to provide contrasting acoustical phenomenon. A coupled volume room is generally defined as a space consisting of a large main volume containing high levels of sound absorption connected through small sonically transparent apertures to a smaller coupled volume with lower absorption. When a sound source is placed in the main volume, this configuration may lead to sound energy being trapped in the coupled volume, which is then released back into the main space at a later time. The delay in sound energy from the coupled volume results in a double-sloped sound decay in the main volume, resulting in intriguing acoustical phenomenon not typically seen in single volume spaces. The real world application of this type of space is most commonly found in concert hall settings. The use of computer modeling to study this relatively complex type of space is a comparatively new development, and the limits of the method have yet to be fully explored. This research focuses on determining the effects of the architectural parameters, absorption level and aperture size, on the room acoustics in coupled volume spaces. A coupled volume concert hall computer model was constructed and analyzed in order to determine these effects. Comparative analysis of several configurations of the model reveals that increased absorption in the coupled volume decreases double slope effect, while the effect generally peaks for a relatively small aperture opening size.
\end{abstract}




\section{Introduction}

If a person were to enter a space and clap their hands once, the first acoustic feature they would probably notice is the way that sound energy lingers in the space for a period of time. This length of time, specifically the time it takes for sound to decay to one millionth of its original intensity is defined as the reverberation time (RT). Normally, room acousticians deal with spaces that are known as single volume spaces, wherein the RT decays in a logarithmic fashion as a function of time. When the sound pressure level (SPL) - a logarithmic quantity - of the decay is plotted against time, a linear decay curve results.

By acoustically linking a secondary volume to a single volume space, the behavior of this decay can be drastically changed. A system utilizing coupled volumes typically consists of two or more spaces that are connected through an acoustically transparent opening known as a coupling aperture. The coupled spaces very often possess categorically different sound absorption characteristics, thus resulting in dissimilar decay times. When the secondary space exhibits a decay time that is longer than that of the main space, sound energy will be fed back into the main space at a later time. This late-arriving energy results in the phenomenon known as double slope decay, referring to the shape of the decay curve depicting SPL plotted as a function of time, as shown in Figure 1. This double slope effect (DSE) results in acoustic conditions that are not typically seen in single volume spaces and may be preferred by listeners.

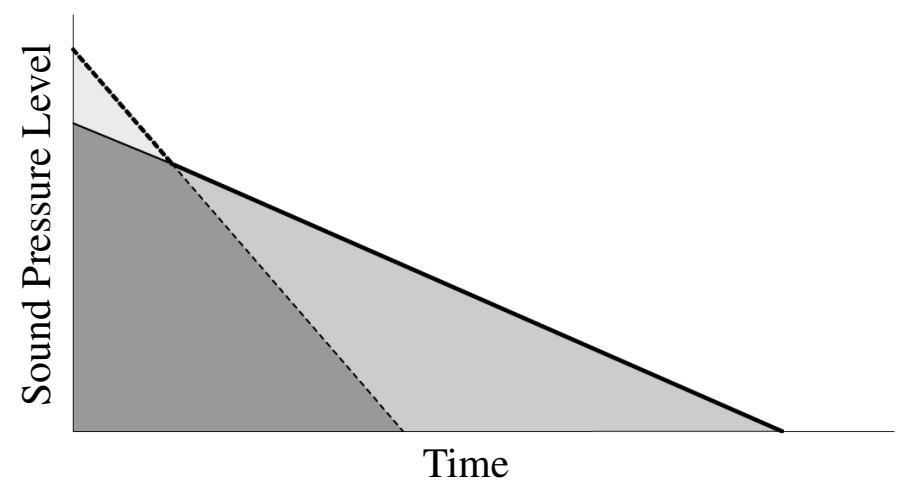

Figure 1. Example double slope decay resulting from a coupled volume space.

\section{Investigation}

In an effort to expand upon previous research into DSE (Eyring 1931, Harrison \& Madaras 2001, Ermann \& Johnson 2002, Summers et. al. 2004), and a preliminary investigation by the authors (Bradley \& Wang 2005), the current investigation focuses on an advanced level computer model of a coupled volume concert hall. This imagined space is based on an amalgamation of features from existing performing arts spaces utilizing coupled volume systems, with architectural parameters that are restricted to real world values. A plan view of the modeled hall is shown in Figure 2, 
with the coupled volume surrounding the main volume of the hall on three sides and separated by a series of doors.

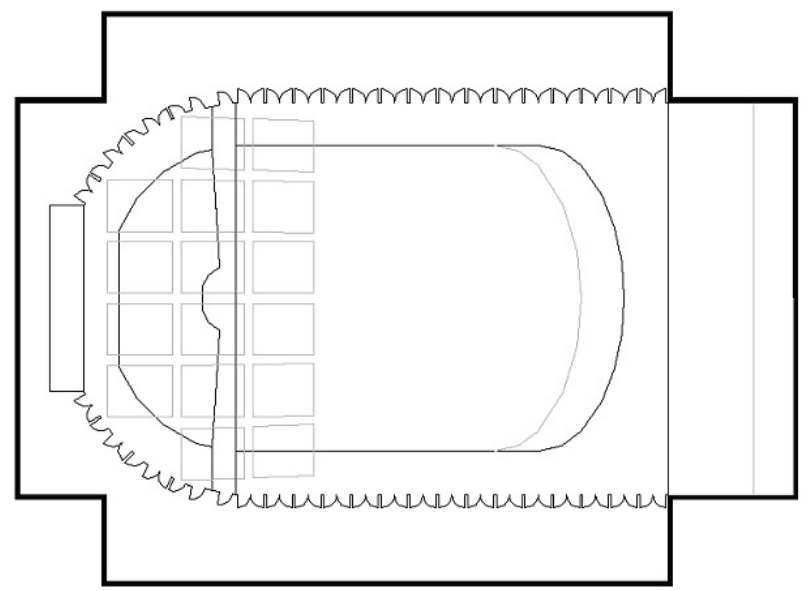

Figure 2. Plan view of computer modeled coupled volume concert hall.

In this study, the two architectural parameters of interest were sound absorption and aperture size. Four levels $(a, b, c$, and $d$ ) of sound absorption ratio between the main and coupled volumes were used, ranging from 0.04 to 0.16 . The size of the aperture opening separating the two volumes, controlled by the number of open doors, was expressed as a percentage of the total surface area in the main volume and assigned seven levels. These levels included one level of $0 \%$, representing a single volume configuration, with the remaining levels ranging from $0.5 \%$ to $10 \%$. The architectural parameter levels are shown in Tables 1 and 2.

Table 1: Absorption Ratio Levels

\begin{tabular}{|c|c|}
\hline Level & Ratio \\
\hline$a$ & 0.04 \\
\hline$b$ & 0.08 \\
\hline$c$ & 0.12 \\
\hline$d$ & 0.16 \\
\hline
\end{tabular}

Table 2: Aperture Opening Size Levels

\begin{tabular}{|c|c|}
\hline Level & \% Total Main Surface Area \\
\hline 0 & $0.0 \%$ \\
\hline 1 & $0.5 \%$ \\
\hline 2 & $1.0 \%$ \\
\hline 3 & $1.5 \%$ \\
\hline 4 & $3.0 \%$ \\
\hline 5 & $6.5 \%$ \\
\hline 6 & $10.0 \%$ \\
\hline
\end{tabular}


This architectural parameter set up resulted in a total of 25 configurations of the coupled volume hall: 6 aperture sizes multiplied by 4 absorption ratios, plus one single volume case. Each configuration of the CAD computer model was constructed and imported into the Odeon (v. 6.5) acoustic simulation modeling program, which generates a room impulse response (RIR) of the model. The RIR contains the time and frequency information needed to analyze the acoustics of the space being modeled. From the RIR of each configuration, visual representations of the decay in each model were constructed and analyzed to determine the effect of the architectural parameters on DSE.

\section{Results:}

A comparative analysis of the visual representations of the decays from each configuration gives a rough indication of the effect of aperture size and absorption ratio on the DSE in the coupled volume concert hall computer model.

\section{Absorption Ratio Results}

The decay profiles for the model configurations utilizing the four different absorption ratios, plus the single volume case, are shown in Figure 3. The single volume decay can be seen as a linear decay with one distinct slope. For absorption ratio level $a$ (0.04), the DSE is the most pronounced. As the absorption ratio increases, or as the absorption in the coupled volume increases, the later portion of the decay is less prominent and the profile converges to the single volume case. This trend follows expectation; as more sound is absorbed in the coupled space, less energy returns to the main volume in the later time window, thus decreasing the distinction of the second slope in the double decay profile.

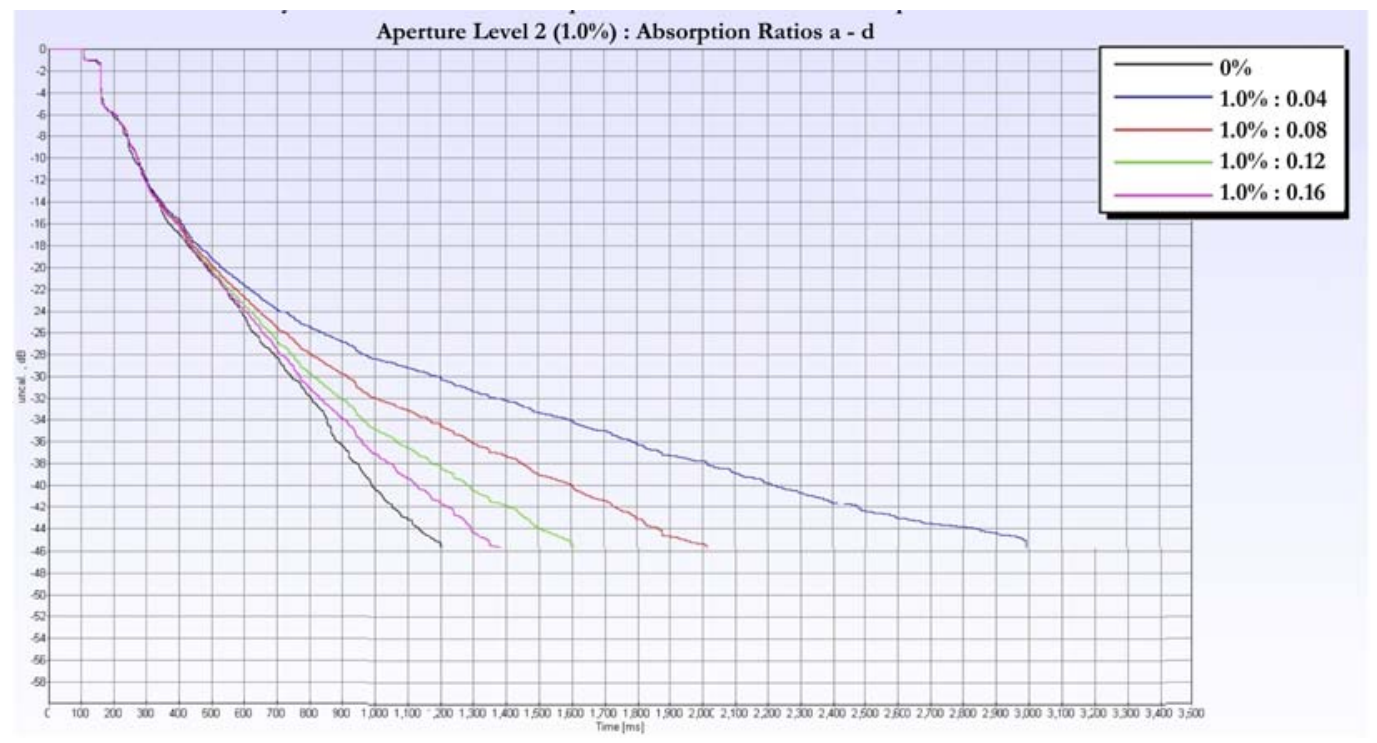

Figure 3. Decay profiles from the coupled volume concert hall computer model for different absorption ratios. 


\section{Aperture Size Results}

The decay profiles for the model configurations utilizing the six different aperture sizes, plus the single volume case, are shown in Figure 4. The aperture level results can be separated into two groups. Levels $1-3(0.5 \%, 1.0 \%$, and $1.5 \%)$ all show pronounced DSE, with the later portion of each level's profile rising higher than the previous. The behavior of levels 4-6 (3.0\%, 6.5\%, and 10.0\%) is markedly different. The decay profile of level 6 , the largest aperture size, appears to follow a single linear decay, although with a much shallower slope than the single volume case. This result follows from the fact that the large aperture size produces a mixing of sound energy between the main and coupled volumes without a temporal delay in their decays. The $3.0 \%$ and $6.5 \%$ aperture sizes still possess DSE, but approach this new single slope decay as the opening size increases.

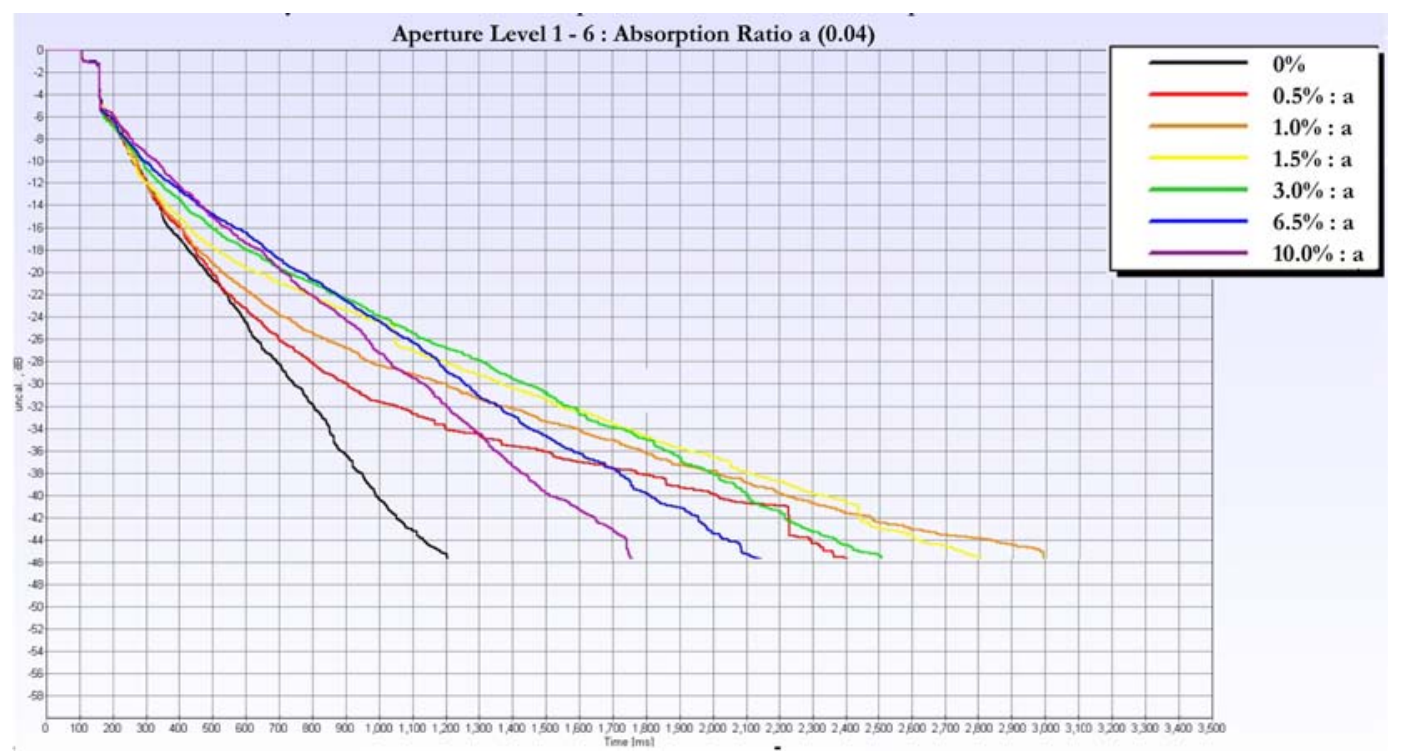

Figure 4. Decay profiles from the coupled volume concert hall computer model for different aperture sizes.

\section{Conclusion and Future Work:}

Several configurations of a coupled volume concert hall computer model were studied to determine the effect of absorption ratio and aperture size on the resulting decay profiles from the space. An increase in absorption ratio showed a decrease in double slope effect. The effect peaked for a relatively small aperture size and approached a single slope decay for large opening sizes.

Further analysis of the RIR's from the computer model can be conducted based on several acoustic objective measures in order to obtain a more quantifiable understanding of the effect of architectural parameter on DSE. Additionally, the RIR's can be convolved with anechoic music to create auralizations (analogous to 
visualizations), which can be used to determine subjective response to double slope decay in coupled volume systems.

\section{References}

Bradley, D. T. and Wang, L. M. (2005). "The effects of simple coupled volume geometry on the objective and subjective results from nonexponential decay." J. Acoust. Soc. Am., 118, 1480-1490.

Ermann, M. and Johnson, M. (2002). "Pilot study: Exposure and materiality of the secondary room and its impact in the impulse response of coupled-volume concert halls." J. Acoust. Soc. Am. 111, 2331(A).

Eyring, C. F. (1931). "Reverberation Time Measurements in Coupled Rooms." J. Acoust. Soc. Am. 3, 181-206.

Harrison, B. and Madaras, G. (2001). "Computer modeling and prediction in the design of coupled volumes for a 1000-seat concert hall at Goshen College, Indiana." J. Acoust. Soc. Am. 109, 2388(A).

Summers, J. E., Torres, R. R., and Shimizu, Y. (2004). "Statistical-acoustics models of energy decay in systems of coupled rooms and their relation to geometrical acoustics," J. Acoust. Soc. Am. 116, 958-969. 